\title{
Genetic dissection of lupus pathogenesis: a recipe for nephrophilic autoantibodies
}

\author{
Chandra Mohan, ${ }^{1}$ Laurence Morel, ${ }^{2}$ Ping Yang, ${ }^{2}$ Hiroshi Watanabe, ${ }^{3}$ Byron Croker, ${ }^{2}$ \\ Gary Gilkeson, ${ }^{3}$ and Edward K. Wakeland ${ }^{1}$

\begin{abstract}
${ }^{1}$ Simmon's Arthritis Research Center and the Center for Immunology, University of Texas-Southwestern Medical School, Dallas, Texas 75235-8884, USA

${ }^{2}$ Department of Pathology, Immunology and Laboratory Medicine, University of Florida, Gainesville, Florida 32610, USA

${ }^{3}$ Medical Research Service, Ralph H. Johnson Veterans Affairs Medical College and the Medical University of South Carolina, Charleston, South Carolina 29425, USA
\end{abstract}

Address correspondence to: Chandra Mohan and Edward K. Wakeland, Simmon's Arthritis Research Center and the Center for Immunology, University of Texas-Southwestern Medical Center, 5323 Harry Hines Boulevard, Dallas, Texas 75235-8884, USA. Phone: (214) 648-9675; Fax: (214) 648-7995; E-mail: Chandra.Mohan@email.swmed.edu and Edward.Wakeland@email.swmed.edu.

Chandra Mohan and Laurence Morel contributed equally to this work.

Received for publication November 17, 1998, and accepted in revised form May 11, 1999.

\begin{abstract}
Sle1 and Sle3 are 2 loci that confer susceptibility to lupus nephritis in the NZM2410 strain of mice. Our previous work has shown that B6.NZMc1 mice, congenic for Sle1, exhibit loss of tolerance to chromatin but do not develop any pathogenic autoantibodies or disease. B6.NZMc7 mice, congenic for Sle3, exhibit low-grade polyclonal B- and T-cell activation, elevated CD4/CD8 ratios, and mildly penetrant glomerulonephritis. In contrast to these monocongenics, the present study reveals that $\mathrm{B} 6 . \mathrm{NZMc} 1 \mid \mathrm{c} 7$ mice, bicongenic for Sle1 and Sle3, exhibit splenomegaly, significantly expanded populations of activated $\mathrm{B}$ and $\mathrm{CD} 4^{+} \mathrm{T}$ cells, and a robust, variegated IgG autoantibody response targeting multiple components of chromatin (including double-stranded DNA), intact glomeruli, and basement membrane matrix antigens. As one might predict, these mice, particularly the females, exhibit highly penetrant glomerulonephritis.

These findings lend strong support to a two-step epistatic model for the formation of pathogenic, nephrophilic autoantibodies in lupus. Whereas loci such as Sle1 may serve to breach tolerance to chromatin, full-blown pathogenic maturation of the autoantibody response appears to require additional input from other loci (such as Sle3) and gender-based factors.
\end{abstract}

J. Clin. Invest. 103:1685-1695 (1999).

\section{Introduction}

The production of antinuclear antibodies (ANAs) is the hallmark of murine and human lupus. Nevertheless, not all classes of ANAs are pathogenic or predictive of disease. Studies in murine models have documented multiple immunologic factors and mechanisms leading to the formation of pathogenic ANAs in lupus (1-3). However, the genetic basis of these different mechanisms and their respective roles in engineering pathogenic ANAs have remained obscure. Recent genetic studies in murine lupus have served to clarify some of these issues.

Susceptibility to lupus in murine models has been mapped to several different loci (recently reviewed in refs. 4-6). Our studies focus on the NZM2410 strain, derived from a cross between the New Zealand black (NZB) and New Zealand white (NZW) strains (7). This lupus-prone strain demonstrates splenomegaly, a prominent expansion of activated $\mathrm{CD}^{+} \mathrm{T}$ cells and $\mathrm{B}$ cells, high-titered ANAs, and early-onset immune-complex glomerulonephritis $(\mathrm{GN})(7,8)$. To map positions of the susceptibility loci for these immunologic traits, a $(\mathrm{NZM} 2410 \times \mathrm{B} 6) \times \mathrm{NZM} 2410$ backcross analysis was undertaken several years ago (9). That linkage analysis revealed that genomic intervals on chromosomes 1 (Sle1), 4 (Sle2), 7 (Sle3), and 17 (Sle4) were strongly linked to lupus nephritis.
The study of B6 mice rendered congenic for these different genomic intervals (Figure 1) recently illuminated their respective roles in lupus pathogenesis (4, 10-14). In B6.NZMc1 mice, the lymphocytes are functionally normal, but Sle 1 breaches tolerance to chromatin, leading to the appearance of high titers of ANAs directed against the most exposed determinants on chromatin, i.e., $\mathrm{H} 2 \mathrm{~A} / \mathrm{H} 2 \mathrm{~B} / \mathrm{DNA}$ subnucleosomes (14). These subnucleosome-specific ANAs show little reactivity to the other epitopes on chromatin, including histone-free doublestranded DNA (dsDNA). Despite having serum ANAs that strongly stain Hep-2 nuclei homogeneously (which is an accepted diagnostic hallmark of lupus), this strain is healthy and does not develop severe GN (12).

In contrast, B6.NZMc7 mice congenic for the NZM2410-derived Sle3 interval, exhibit elevated serum levels of polyclonal/polyreactive IgM and IgG antibodies, with low-grade reactivity to all chromatin components, accompanied by an $18 \%$ incidence of severe immune-complex GN (12). More recent studies reveal an interesting spectrum of immunologic aberrations in this strain (15). Specifically, these mice show a stronger humoral response upon antigenic challenge. Ex vivo, their $\mathrm{T}$ and $\mathrm{B}$ cells exhibit an activated phenotype. B6.NZMc7 $T$ cells show increased proliferation in response to anti-CD3 and rIL-2, elevated CD4/CD8 
ratios, and impaired activation- and Fas-induced T-cell death, when compared with age-matched B6 controls.

Despite these interesting phenotypes, neither of these monocongenic strains - B6.NZMc1 or B6.NZMc7 exhibit serologic, cellular, or histopathologic features of lupus that compare to the severity in the affected parental NZM2410 strain. Indeed, the original mapping study had already suggested that phenotypic expression of this disease is governed by a threshold-liability model of inheritance, in which disease susceptibility rapidly escalates when individual mice coinherit 2 or more susceptibility loci. The availability of the $\mathrm{B} 6$ congenic strains bearing the different susceptibility loci now allows us to test this prediction directly. Using the bicongenic strain B6.NZMc1 |c7, this study examines how the coexpression of Sle1 with Sle3 impacts the serologic, cellular, and histopathologic component phenotypes of lupus.

\section{Methods}

Mice. C57BL/6 (B6) mice were obtained from The Jackson Laboratory (Bar Harbor, Maine, USA) and then were bred in our animal colony. The derivation of $\mathrm{B} 6$ congenic mice bearing NZM2410-derived lupus susceptibility intervals has been detailed previously (11). B6.NZMc1 mice are C57BL/6 mice congenic for a 37-cM interval on murine chromosome 1 , spanning the $95 \%$ confidence interval flanking Sle1, with termini at D1MIT101 and D1MIT55. The immunologic phenotypes of this strain have been reported recently $(12,14)$. B6.NZMc7 mice are C57BL/6 mice congenic for a $40-\mathrm{cM}$ interval on murine chromosome 7 , spanning the $95 \%$ confidence interval flanking Sle3, with termini at D7MIT56 and D7MIT62. The immunologic phenotypes of this strain have also been reported recently $(12,15)$. Both congenic intervals are derived from the NZW parent of the NZM2410 strain. B6.NZMc1 |c7 mice, bicongenic for both the study intervals, were derived by intercrossing the monocongenic strains and breeding for mice that were homozygous across both susceptibility intervals. All mice used for this study were bred and housed in a conventional animal colony. Both male and female mice were used, and any observed sex differences are indicated. Unless otherwise indicated, the depicted experiments were conducted with 9- to 12-month-old mice. In the case of the NZM2410 strain, these mice were sacrificed when moribund, usually at 5-8 months of age.

Cell preparation and culture. Splenocytes were depleted of red blood cells using $0.83 \% \mathrm{NH}_{4} \mathrm{Cl}$, and single-cell suspensions were prepared for culture or flow cytometric analysis, as described below. The ability of splenic $\mathrm{T}$ cells to drive B-cell autoantibody production in vitro was assessed by coculture assays, as described previously (14). For the experiments shown in Figure $3 \mathrm{c}$, splenic $\mathrm{B}$ cells, and syngeneic $\mathrm{CD} 4^{+}$and $\mathrm{CD}^{+} \mathrm{T}$ cells, were purified by FACS ${ }^{\circledR}$ sorting. $0.5 \times 10^{6}$ splenic T cells were cocultured with $0.5 \times 10^{6} \mathrm{~B}$ cells in $200-\mu \mathrm{L}$ culture volumes of serumfree HL-1 media (BioWhittaker Inc., Walkersville, Maryland, USA) at $37^{\circ} \mathrm{C}$. Supernatants were harvested 7 days after culture, diluted 1:2, and then assayed for total IgG or IgG ANAs by ELISA, as described below.

Flow cytometric analysis and antibodies. Flow cytometric analysis was performed as described previously $(13,15)$. Briefly, cells were first blocked with staining medium (PBS, $5 \%$ horse serum, and $0.05 \%$ azide) containing $10 \%$ normal rabbit serum. Cells were then stained on ice with optimal amounts of FITC, phycoerythrin, or biotin-conjugated primary antibodies diluted in staining medium for 30 minutes. The following dye- or biotin-coupled antibodies were obtained from PharMingen (San Diego, California, USA): CD4 (RM4-5), CD5 (53-7.3), CD8 (Ly-2), CD23 (B3B4), CD24 (M1/69), CD25 (7D4), CD43 (S7), CD44 (IM7), CD45R/B220 (RA3-6B2), CD62L (MEL14), CD69 (H1.2F3), CD80/B7-1 (16-10A1), and CD86/B7-2 (GL1); these antibodies were used at pretitrated dilutions. After 2 washes, the biotinconjugated antibodies were revealed using streptavidin-Tricolor (Caltag Laboratories Inc., Burlingame, California, USA) or streptavidin-Quantum red (Sigma Chemical Co., St. Louis, Missouri, USA). Cell staining was analyzed using a FACScan (Becton Dickinson Immunocytometry Systems, San Jose, California, USA). Dead cells were excluded on the basis of scatter characteristics and propidium iodide uptake, and 10,000 events were acquired per sample. B-cell blasts were defined by their size on the forward-scatter channel, as a distinct cell population (>150 units on a linear forward-scatter channel) that was larger than the rest of the $\mathrm{B}_{22} 20^{+}$cells (which typically sized $<150$ units on the forward-scatter channel). Cell sorting was conducted using a FACStar (Becton Dickinson Immunocytometry Systems). B cells were sorted after staining for B220. Likewise, $\mathrm{CD} 4^{+}$and $\mathrm{CD}^{+} \mathrm{T}$ cells were sorted using anti-CD4 or anti-CD8 antibodies, respectively. Sorted cells were typically $>95 \%$ pure.

ELISA for total immunoglobulin. Total serum IgM and IgG iso-

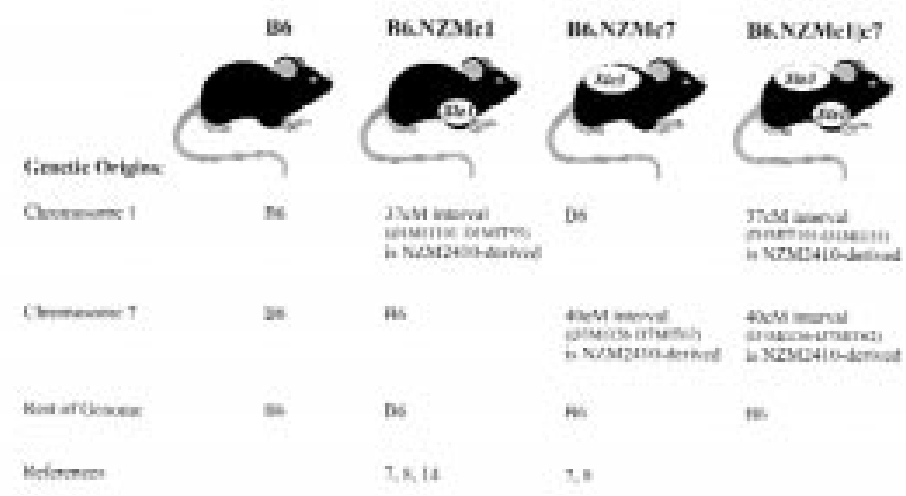

Figure 1

B6 congenics bearing NZM-derived lupus susceptibility intervals. The present study is based on 3 B6 congenics bearing different combinations of lupus susceptibility intervals. Lupus susceptibility in the NZM2410 lupus strain maps to loci on chromosomes 1 (Sle 1), 4 (Sle2), 7 (Sle3), and 17 (Sle4). Our understanding of the contributions of these individual loci has been greatly boosted by the generation of B6 mice congenic for these individual susceptibility intervals. Thus, B6.NZMc1 mice are congenic for Sle1, whereas B6.NZMc7 mice are congenic for Sle3. The immunologic phenotypes of these 2 moncongenic strains have been detailed recently $(12,14)$. The B6.NZMc1 $\mid c 7$ strain, bicongenic for these susceptibility intervals, is the subject of the present communication. 


\section{Figure 2}

B6.NZMc1 |c7T cells have an activated/memory phenotype. The top row of two-dimensional FACS plots depicts the percentages of $\mathrm{CD}^{+}$and $\mathrm{CD}^{+} \mathrm{T}$ cells in 9- to 12-month-old spleens from the 5 different strains. Shown in the top right quadrants (top row) are the percent CD4 over percent CD8 T cells in the respective plots. The strains did not differ in the intensity of CD4 or CD8 expression, and all plot-to-plot variations seen in the figure reflect variations between experiments. The bottom 3 rows (top, middle, and bottom) of histograms display the expression profiles of CD45RB, CD62L (L-selectin), and CD69, respectively, on gated $C D 4^{+} T$ cells from 9- to 12-month-old spleens from the different strains (filled histograms). The open histograms represent the background staining obtained using the isotype control antibodies. Plots are representative of data obtained from a large cohort of 9- to 12-month-old mice, as detailed in Table 2.

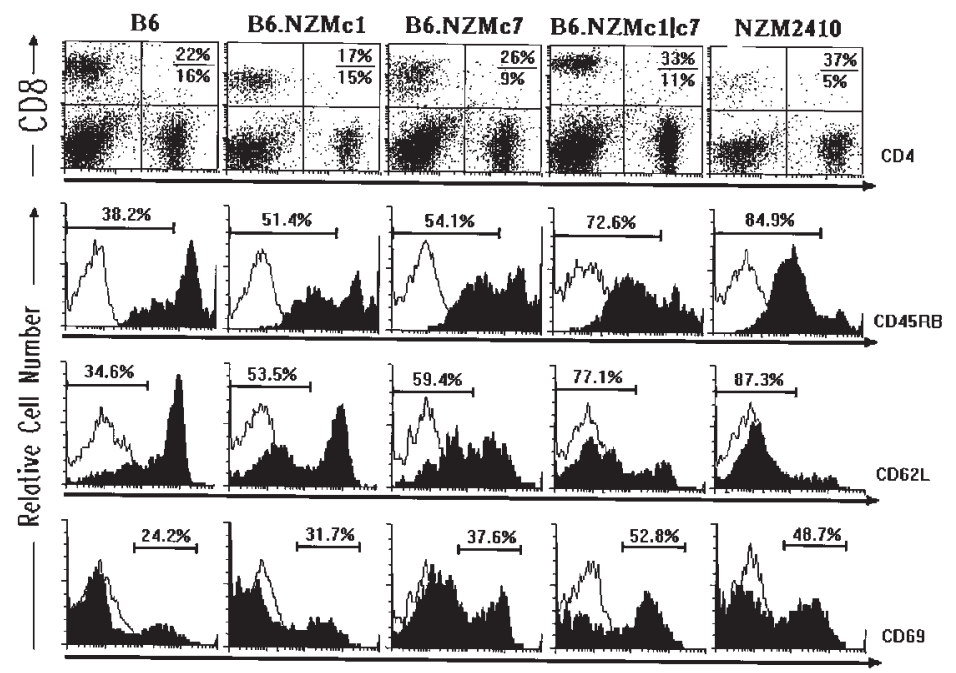

type/subclass levels were assayed using a sandwich ELISA. Briefly, goat anti-mouse IgM, IgG, IgG1, IgG2a, IgG2b, or IgG3 (Boehringer Mannheim Biochemicals, Indianapolis, Indiana, USA; or PharMingen) was first coated onto Immulon I plates and then blocked. Sera were diluted serially and added to the plates for 2 hours at room temperature. Bound immunoglobulin was revealed with alkaline phosphatase-conjugated goat anti-mouse IgM, IgG, IgG1, IgG2a, IgG2b, or IgG3 antibodies (Boehringer Mannheim Biochemicals or PharMingen), using $p$-nitrophenyl phosphate (pNPP) as a substrate. Serial dilutions of isotype-specific immunoglobulin standards were also added to each plate for quantitation and interplate standardization.

ELISA for ANAs. The anti-dsDNA and anti-subnucleosome ELISAs were carried out as described before (14, 16-18). Briefly, Immulon II plates (Dynatech Laboratories, Chantilly, Virginia, USA), precoated with methylated BSA, were coated overnight with $50 \mu \mathrm{g} / \mathrm{mL}$ dsDNA (Sigma Chemical Co.), dissolved in PBS, and then filtered through cellulose acetate before use. The plates were then postcoated with $10 \mu \mathrm{g} / \mathrm{mL}$ of either histone $\mathrm{H} 1$, a $1: 1$ mixture of histones $\mathrm{H} 2 \mathrm{~A} / \mathrm{H} 2 \mathrm{~B}$, a 1:1 mixture of histones $\mathrm{H} 3 / \mathrm{H} 4$, or total histones (a mixture of all histones) overnight at $4^{\circ} \mathrm{C}$. All histones were purchased from Boehringer Mannheim Biochemicals. Thus, H2A/H2B/DNA refers to dsDNA postcoated with a mixture of histones $\mathrm{H} 2 \mathrm{~A}$ and $\mathrm{H} 2 \mathrm{~B}$, with a similar nomenclature being adopted for the other subnucleosomes. These different nucleosomal antigens (dsDNA, H2A/H2B/DNA, $\mathrm{H} 3 / \mathrm{H} 4 / \mathrm{DNA}$, and $\mathrm{H} 1 / \mathrm{DNA}$ ) were coated onto serial wells of the same ELISA plates, facilitating the comparison of the relative reactivities of any given serum to these different epitopes. The concentrations of antigens used in these ELISAs have been shown to saturate all available binding sites (17). After blocking with $\mathrm{PBS} / 3 \% \mathrm{BSA} / 0.1 \%$ gelatin/3 mM EDTA, $1: 100$ dilutions of the test sera (or 1:2 dilutions of culture supernatants) were incubated in duplicate for 2 hours at room temperature. Bound IgG was detected with alkaline phosphatase-conjugated anti-mouse IgG (Jackson ImmunoResearch Laboratories Inc., West Grove, Pennsylvania, USA), using pNPP as a substrate. Raw OD was converted to $\mathrm{U} / \mathrm{mL}$, using a positive control serum from an NZM2410 mouse. The reactivity of a 1:100 dilution of this serum was arbitrarily set to $100 \mathrm{U} / \mathrm{mL}$. This control serum showed equally strong $(\mathrm{OD})$ reactivities to all the tested subnucleosomal antigens, again allowing the relative reactivities of the test sera to the different antigens to be compared with each other. Sera with reactivities stronger than the test standard were diluted further and reassayed.

Matrix antigen and glomerular-binding ELISA. Reactivity to basement membrane antigens was detected by ELISA, following the same steps as detailed above, except for the antigens coated onto the ELISA plates. Matrigel, heparan sulfate, collagen IV, and laminin (purchased from Becton Dickinson Immunocytometry Systems or Sigma Chemical Co.) were coated onto ELISA plates at $10 \mu \mathrm{g} / \mathrm{mL}$. Matrigel is a soluble basement membrane preparation rich in extracellular matrix proteins that is extracted from mouse Engelbreth-Holm-Swarm sarcoma. Its use as a glomerular basement membrane substitute for ELISA assays is well documented (19). Penetrance was defined as the percentage of mice in each study group exhibiting serum autoantibody levels at least $2 \mathrm{SD}$ above the mean levels present in a test panel of $12 \mathrm{~B} 6$ mice, aged 9 months.

The glomerular-binding ELISA was performed as described $(20,21)$. Briefly, ELISA plates were first coated with sonicated whole rat glomerular extract and then blocked. Test sera were added in serial dilutions starting at a 1:100 dilution, and any bound IgG was revealed using peroxidase-coupled antimouse $\operatorname{IgG}$ and the peroxidase substrate TMB $\left(3,3^{\prime}, 5,5^{\prime}\right.$ tetramethylbenzidine). Sera with $\mathrm{OD}_{380}$ values in excess of 0.200 were deemed positive, as the latter value represents 2 SD above the mean, basal reactivity seen in $\mathrm{BALB} / \mathrm{c}$ control sera in this series of assays.

Histology. Mice were sacrificed at 12 months of age (or earlier, if evidently in distress), and kidneys, spleens, and other internal organs were fixed, sectioned, and stained with hema-

\section{Table 1}

Spleen weights in 9- to 12-month-old B6 congenics and controls

B6

B6.NZMc1

B6.NZMc7

B6.NZMc1 1 c7 males B6.NZMc1 $\mid$ c7 females 48 NZM2410 *

Shown in the table are the mean \pm SEM weights of spleens in the indicated num bers $(n)$ of mice at 9-12 months of age. Also shown are the $P$ values obtained in comparing the weights with those of B6 or NZM2410, using the one-tailed Student's $t$-test. *These mice were 5-8 months. old, by which age more than $80 \%$ exhibit clinical nephritis.NS, not significant 


\section{Figure 3}

B6.NZMc1 $\mid$ c7 B cells produce IgG ANAs. Total splenocytes from 9- to 12 -month-old mice $\left(10^{6}\right.$ cells in $200 \mu \mathrm{L}$ media per well) were cultured for 7 days. At the end of the culture period, the culture supernatants were assayed by ELISA for total $\lg G(\mathbf{a})$ and $\lg G$ ANAs specific for dsDNA, or for $\mathrm{H} 2 \mathrm{~A} / \mathrm{H} 2 \mathrm{~B} / \mathrm{DNA}$ (b). Each bar represents the mean ( \pm SEM) levels of IgG antibodies (total or antigen specific) present in triplicate splenocyte cultures from the respective strains. B6.NZMc1 $\mid c 7$ splenocytes produced significantly more total $\lg G(P<0.02)$, IgG antidsDNA $(P<0.01)$, and IgG anti-H2A/H2B/DNA $(P<0.006)$ compared with $\mathrm{B} 6$ or B6.NZMc7 splenocytes. Compared with B6.NZMc1 splenocytes, B6.NZMc1|c7 splenocytes secreted significantly increased amounts of anti-dsDNA $(P<0.01)$, but not anti-H2A/H2B/DNA ANAs, in culture. (c) B6.NZMc1|c7 B cells, FACS-sorted from 9-month-old spleens, were cultured with or without FACS-sorted syngeneic splenic CD4 ${ }^{+}$or CD $8^{+} \mathrm{T}$ cells, or LPS $(10 \mu \mathrm{g} / \mathrm{mL}) .5 \times 10^{5}$ cells of each type were added per well in 200- $\mu \mathrm{L}$ culture volumes. Each bar represents the triplicate mean ( \pm SEM) IgG anti-dsDNA ANAs secreted in culture after 7 days of culture. $B$ cells cocultured with $C D 4^{+} T$ cells produced significantly higher levels of ANAs compared with the cultures without $T$ cells or with $\mathrm{CD} 8^{+} \mathrm{T}$ cells $(P<0.03)$. Cultures with $\mathrm{CD} 4^{+}$or $\mathrm{CD} 8^{+} \mathrm{T}$ cells alone typically exhibited ANA levels of $<2 \mathrm{U} / \mathrm{mL}$. Data are representative of 3 independent experiments.

toxylin/eosin and periodic acid-Schiff. This method routinely provides $\sim 100$ glomeruli in each section. Multiple sections were examined in a blinded fashion by light microscopy for indication of inflammation and tissue damage, as described before (22). Briefly, GN was quantified on a 0-4 scale, in which the grades $1,2,3$, and 4 are accorded when $1-10 \%, 11-25 \%, 26-50 \%$, and $>50 \%$ of the glomeruli are affected, respectively. GN of grades 3 and 4 is referred to in this communication as severe GN. Glomerular lesions were also classified as mesangiopathic, capillary hyaline, proliferative, membranous, or crescentic, as described before (23). Spleens were examined for primary follicles, germinal centers, atypical hyperplasia, and lymphomas.

Statistics. Data obtained for the B6.NZMc1 $\mid \mathrm{c} 7$ mice were compared with data from the control B6 or monocongenic mice using the Student's $t$ test, unless otherwise indicated. For all experiments, the mean and SEM are also shown.

\section{Results}

Cellular phenotypes impacted by Sle1 and Sle3. Splenomegaly is a prominent feature of several murine lupus strains, including the NZM2410 strain (22). Although B6.NZMc7 mice exhibit no splenomegaly, 9- to 12month-old B6.NZMc1 mice had significantly larger spleens compared with B6 mice (161 vs. $100 \mathrm{mg} ; P$ < $0.016)$, as presented in Table 1 . This phenotype was even more pronounced in the B6.NZMc1|c7 bicongenic strain, whose spleens were significantly larger than those of age-matched B6 $(P<0.004)$, B6.NZMc1 $(P<0.04)$, and B6.NZMc7 $(P<0.008)$ strains. In particular, as Table 1 shows, B6.NZMc1 $\mid$ c7 females had spleen weights that were comparable with those of NZM2410 mice and significantly larger than those of B6.NZMc1 $\mid$ c7 males $(P<$ $0.025)$. In contrast, lymphadenopathy was not a consistent feature in this strain (data not shown).

Table 2 summarizes the features of splenic lymphocytes in the bicongenic and relevant monocongenic strains. The larger B6.NZMc1|c7 spleens were composed of significantly increased numbers of splenocytes com- a

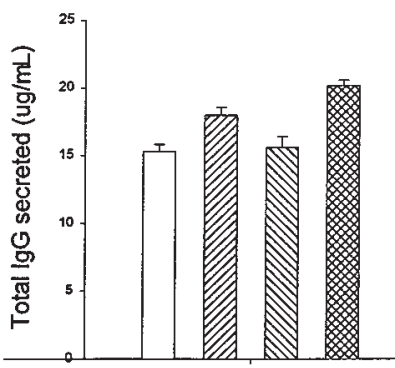

B6

एבZZS B6.NZMc1 एकाष B6.NZMc7

b B6.NZMc1c7

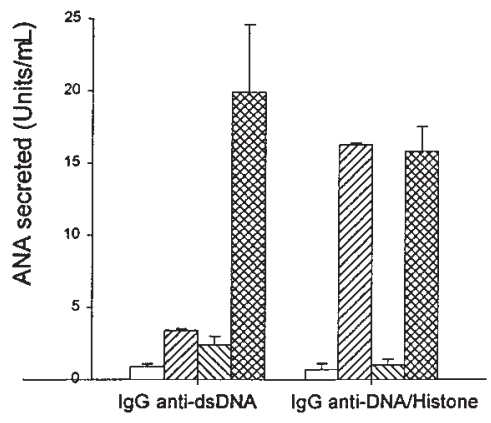

C

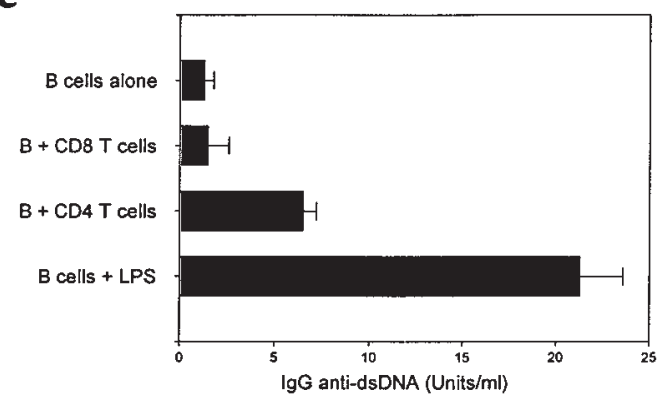

pared with age-matched B6, B6.NZMc1, and B6.NZMc7 mice. Although the percentage of $B$ cells in B6.NZMc1|c7 spleens was not significantly different from that of control spleens, absolute numbers of $B$ cells were increased. In addition, B6.NZMc1 $\mid$ c7 splenic B cells appeared preactivated, as judged by their size and surface phenotype. Thus, $42.3 \%$ of all $\mathrm{B} 220^{+}$splenocytes in B6.NZMc1 |c7 mice were blasts, with increased expression of B7-2, I-A ${ }^{\mathrm{b}}$, and CD44 (Table 2 and data not shown). From Table 2, it can be deduced that B6.NZMc1 | c7 spleens harbor a 3- to 4-fold increase in the absolute numbers of B-cell blasts, and this is comparable to the numbers and percentages in the NZM2410 spleen. In addition, the NZM2410 strain, unlike the B6.NZMc1|c7 strain, exhibited a significant expansion of splenic B1a cells, a phenotype that may be attributed, at least in part, to Sle 2 on chromosome $4(8,13)$.

B6.NZMc1|c7 spleens also exhibited significantly increased $\mathrm{CD}^{+} \mathrm{T}$-cell percentages and reduced $\mathrm{CD} 8^{+} \mathrm{T}$ cell percentages relative to the controls (Table 2 ). This translates into a 2- to 3 -fold increase in the absolute numbers of $\mathrm{CD}^{+} \mathrm{T}$ cells and $\mathrm{CD} 4 / \mathrm{CD} 8$ ratios in B6.NZMc1|c7 spleens. Furthermore, B6.NZMc1|c7 
spleens also exhibited a distinct expansion of $\mathrm{T}$ cells with an activated/memory phenotype, i.e., cells that were $\mathrm{CD}_{69}{ }^{+}, \mathrm{CD} 45 \mathrm{RB}^{\text {low }}$, and CD62L $\mathrm{L}^{\text {low }}$ (Table 2 and Figure 2). Although $\mathrm{CD}^{+} \mathrm{T}$ cells exhibited a similar trend, this phenotype was more distinct with $\mathrm{CD} 4^{+} \mathrm{T}$ cells, as displayed in Figure 2 and Table 2. Indeed, this expansion of activated $\mathrm{CD} 4^{+} \mathrm{T}$ cells was apparent even at earlier ages. Thus, 4- to 6-month-old B6.NZMc1|c7 mice had a mean of $14.7 \times 10^{6} \mathrm{CD}^{+} \mathrm{CD} 69^{+} \mathrm{T}$ cells per spleen $\left(\mathrm{SEM}=3.1 \times 10^{6} ; n=25\right)$, significantly higher than the numbers found in age-matched B6 (mean \pm SEM $=3.5 \pm 0.4 \times 10^{6}$ cells per spleen; $\left.n=18, P<0.002\right)$, B6.NZMc1 (mean $\pm \mathrm{SEM}=3.3 \pm 0.4 \times 10^{6}$ cells per spleen; $n=14, P<0.02$ ), and B6.NZMc7 mice (mean \pm $\mathrm{SEM}=6.3 \pm 0.6 \times 10^{6}$ cells per spleen; $\left.n=15, P<0.01\right)$. This expansion of activated/memory $\mathrm{CD}^{+} \mathrm{T}$ cells was also noted in age-matched NZM2410 spleens (mean \pm $\mathrm{SEM}=20.9 \pm 6.7 \times 10^{6} \mathrm{CD}^{+} \mathrm{CD}^{2} 9^{+} \mathrm{T}$ cells per spleen; $n=12$ ). Although the spleens from the NZM2410 lupus strain had total cell counts similar to those of B6.NZMc1|c7 spleens, these same phenotypes were even more pronounced in the NZM2410 strain. Thus, for example, NZM2410 spleens exhibited significantly lower $\mathrm{CD}^{+} \mathrm{T}$-cell percentages $(P<0.0001)$, higher $\mathrm{CD}^{+} \mathrm{T}$-cell percentages $(P<0.006)$, and higher CD4/CD8 ratios $(P<0.0001)$ compared with B6.NZMc1 $\mid$ c7 spleens (Table 2).

Although the cellular phenotypes were more pronounced in some female B6.NZMc1|c7 mice, no statistically significant sex differences were noted in these phenotypes among the 9- to 12-month-old B6.NZMc1|c7 mice studied. However, sex differences in these phenotypes were more apparent in younger mice. Thus, compared with 4- to 6-month-old B6.NZMc1|c7 males $(n=$ $13)$, age-matched females $(n=12)$ had significantly higher splenic CD4/CD8 ratios (3.3 vs. $2.1 ; P<0.01$ ), a higher percentage of $\mathrm{CD} 69^{+}$splenic $\mathrm{CD} 4^{+} \mathrm{T}$ cells $(43.6 \%$ vs. $34.8 \% ; P<0.03$ ), and higher percentages of splenic B-cell blasts $(33.1 \%$ vs. $21.3 \% ; P<0.01)$. It thus appears that the combined action of Sle 1 and Sle3 leads to a heightened level of lymphocytic activation, with this phenomenon happening earlier in females.

Consistent with their activated surface phenotype, B6.NZMc1|c7 splenocytes secreted more IgG in culture compared with splenocytes from B6 and B6.NZMc7 mice $(P \leq 0.02)$, but not more than B6.NZMc1 splenocytes $(P \geq$ 0.09 ), using the two-tailed Student's $t$ test (Figure 3a). This increase was even more significant when nuclear antigen-specific IgG was examined. As shown in Figure 3b, whereas B6.NZMc1 splenocytes also secreted anti$\mathrm{H} 2 \mathrm{~A} / \mathrm{H} 2 \mathrm{~B} / \mathrm{DNA}$ ANAs in culture, the B6.NZMc1|c7 splenocytes were the only ones to secrete significant amounts of anti-dsDNA ANAs $(P<0.01)$. That this phenotype is T-cell driven is supported by in vitro helper assays that demonstrate that FACS-sorted B6.NZMc1|c7 $B$ cells secreted significantly more anti-dsDNA ANAs when cocultured with syngeneic $\mathrm{CD}^{+}$, but not $\mathrm{CD}^{+}, \mathrm{T}$ cells $(P<0.03$; Figure $3 c)$.

Serologic phenotypes impacted by Sle1 and Sle3. Given the increased activation status of B6.NZMc1|c7 lymphocytes and their potential to produce ANAs in culture, we next asked how the combined action of Sle1 and Sle3

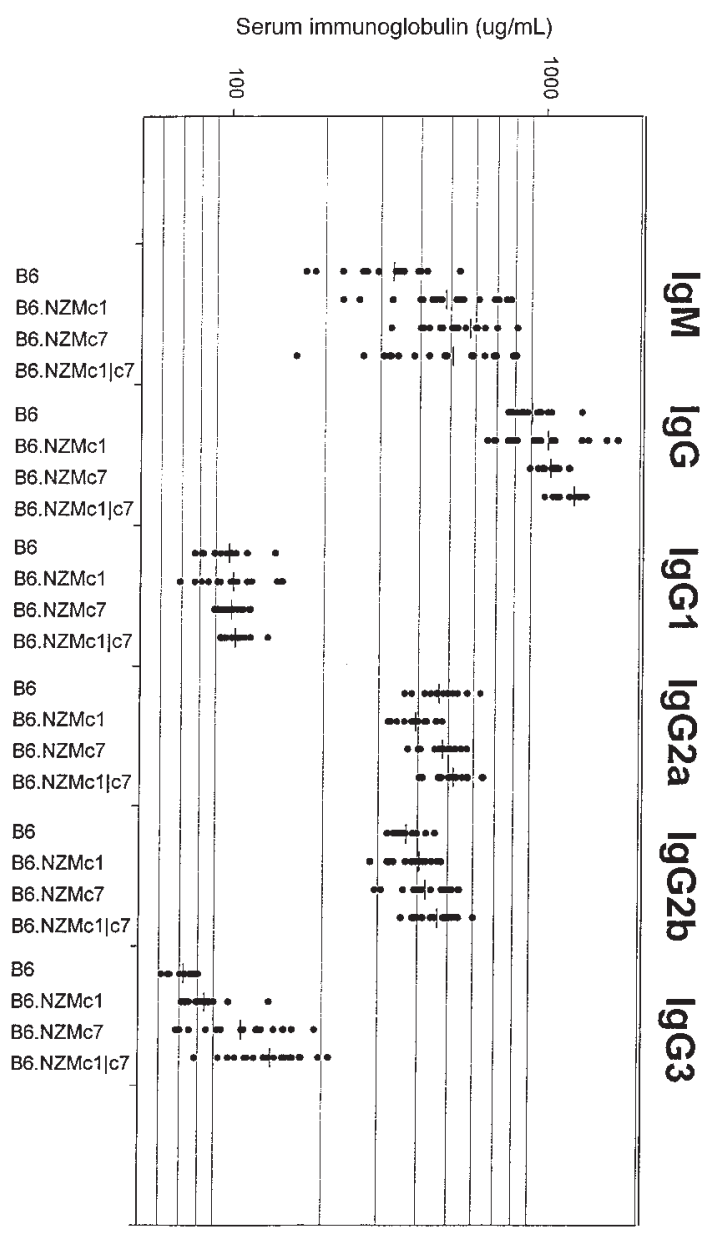

\section{Figure 4}

B6.NZMc1 |c7 mice exhibit hypergammaglobulinemia. Plotted are the total serum IgM, IgG, IgG1, IgG2a, IgG2b, and IgG3 levels in 9- to 12-month-old B6 $(n=15), \mathrm{B} 6 . \mathrm{NZMc1}(n=19), \mathrm{B} 6 . \mathrm{NZMc7}(n=20)$, and B6.NZMc1 $\mid c 7$ $(n=20)$ mice. B6.NZMc1 and B6.NZMc7 mice displayed significantly higher levels of total serum $\operatorname{lgM}$ and $\operatorname{lgG}$, as reported previously (12). B6.NZMc1 $\mid c 7$ mice had significantly higher levels of total serum $\operatorname{lgG}$, but not IgM, compared with B6.NZMc1 $(P<0.015)$ and B6.NZMc7 $(P<$ $0.00005)$. This increase in total serum $\lg G$ was paralleled by significant increases in total serum $\operatorname{lgG} 2 \mathrm{a}(P<0.01), \operatorname{lgG} 2 \mathrm{~b}(P<0.002)$, and $\lg \mathrm{G} 3(P<$ $0.0001)$ compared with B6 and B6.NZMc1 mice, with the B6.NZMc7 mice exhibiting intermediate levels of these subclasses. No sex differences were noted in serum immunoglobulin levels in these strains.

impacted total, as well as nuclear antigen-specific, serum immunoglobulins. As Figure 4 shows, B6.NZMc1|c7 mice exhibited significantly elevated serum IgG (but not IgM) levels when compared with B6.NZMc1 $(P<0.015)$ and B6.NZMc7 $(P<0.00005)$ mice. This increase in total serum IgG was paralleled by significant increases in total serum IgG2a $(P<0.01)$, IgG2b $(P<0.002)$, and IgG3 $(P<$ $0.0001)$ compared with B6 and B6.NZMc1 mice, with the B6.NZMc7 mice exhibiting intermediate levels of these IgG subclasses. This could be of importance, in view of the documented pathogenic relevance of IgG2a and IgG3 autoantibodies in inflicting end-organ pathology in lupus (22-24). No sex differences were noted in serum immunoglobulin levels in these strains.

Given the profiles of ANAs in the monocongenic 
a

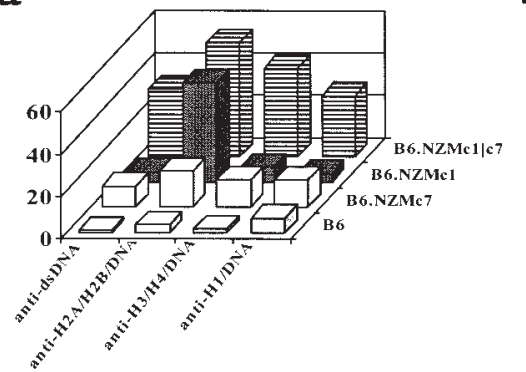

b

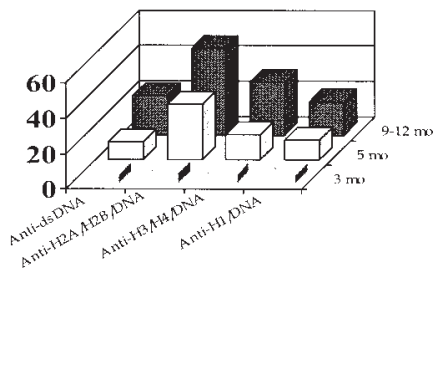

C

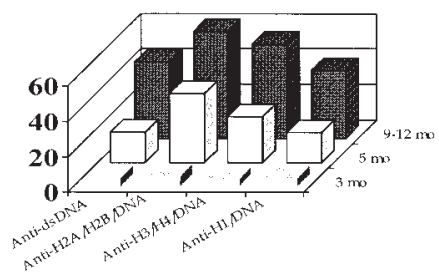

Figure 5

Sle1 and Sle3 shape the emerging ANA profile. (a) Subnucleosome-specific ANAs in serum were assayed by ELISA. The bars represent the mean serum ANA levels $(\mathrm{U} / \mathrm{mL})$ present in 9- to 12-month-old B6 $(n=14)$, B6.NZMc1 $(n=15)$, B6.NZMc7 $(n=18)$, and B6.NZMc1 $\mid c 7$ ( $n=37)$. B6.NZMc7 sera bound equally well (albeit at low levels) to all 4 subnucleosome complexes, whereas B6.NZMc1 sera displayed especially strong reactivities to $\mathrm{H} 2 \mathrm{~A} / \mathrm{H} 2 \mathrm{~B} / \mathrm{DNA}$ subnucleosomes, as reported previously (14). In addition to reacting strongly to $\mathrm{H} 2 \mathrm{~A} / \mathrm{H} 2 \mathrm{~B} / \mathrm{DNA}$ subnucleosomes, sera from the bicongenic B6.NZMc1 $\mid c 7$ strain also showed significantly stronger reactivities to H3/H4/DNA $(P<0.003), \mathrm{H} 1 / \mathrm{DNA}(P<0.04)$, and dsDNA $(P<$ $0.03)$ compared with the monocongenic strains. (b and $\mathbf{c})$ Subnucleosome-specific ANA levels present in 3- $(n=15), 5-(n=20-25)$, and 9- to $12-$ month-old $(n=18)$ B6.NZMc1 $\mid c 7$ males (b) and females (c). Five-month-old female B6.NZMc1|c7 mice had significantly higher levels of anti-dsDNA $(P<0.03)$, anti-H3/H4/DNA $(P<0.003)$, and anti-H1/DNA $(P<0.04)$ ANAs compared with age-matched males. This was also true for $9-$ to $12-$ month-old females: the corresponding $P$ values for the 3 classes of ANAs were $0.008,0.003$, and 0.002 , respectively.

strains $(12,14)$, and the elevated total serum IgG in the B6.NZMc1|c7 mice, we next examined the ANA profiles in the bicongenic strain. As shown in Figure $5 \mathrm{a}$, the B6.NZMc1 and B6.NZMc7 sera differed in the fine specificity profiles of their ANAs. Whereas B6.NZMc7 sera exhibited low-grade reactivity to all tested chromatin components, B6.NZMc1 sera showed preferential reactivity to $\mathrm{H} 2 \mathrm{~A} / \mathrm{H} 2 \mathrm{~B} / \mathrm{DNA}$ subnucleosomes, as reported previously (14). Interestingly, B6.NZMc1|c7 sera displayed strong reactivity to all chromatin components, just as reported for NZM2410 lupus sera (14). Indeed, as shown in Figure 5, b and c, the ANA specificity profiles in B6.NZMc1 $\mid c 7$ mice appear to evolve over time, showing the $\mathrm{H} 2 \mathrm{~A} / \mathrm{H} 2 \mathrm{~B} / \mathrm{DNA}$ preference at earlier age points, with greater involvement of the other epitopes at later ages. It is also intriguing to note that female mice exhibit a more extensive spreading of the ANA response beyond the initially targeted $\mathrm{H} 2 \mathrm{~A} / \mathrm{H} 2 \mathrm{~B} / \mathrm{DNA}$ subnucleosomes. Thus, sera from 5- and 9-month-old female B6.NZMc1 |c7 exhibited significantly higher levels of ANAs specific for dsDNA $(P<0.03), \mathrm{H} 3 / \mathrm{H} 4 / \mathrm{DNA}(P<$ $0.003)$, and H1/DNA subnucleosomes $(P<0.04)$ compared with age-matched males (Figure 5, b and c). Thus, compared with the Sle1-bearing monocongenics, the additional impact of Sle3 (and presumably, female sex hormones) allows the ANA response to spread to other subnucleosomal epitopes, including dsDNA.

Contributions of Sle 1 and Sle 3 to nephrophilic autoantibodies and GN. Thus, in terms of its cellular and serologic phenotypes, B6.NZMc1 $\mid \mathrm{c} 7$ mice (especially the females) closely resemble the NZM2410 strain. This led us to the next 2 related questions. One, what is the pathogenic relevance of the ANAs seen in the B6.NZMc1|c7 mice? And, two, do these mice develop GN? Studies within the recent past have demonstrated that the ability of autoantibodies (or ANAs) to bind glomeruli in vitro correlates well with their potential to inflict renal pathology in vivo $(21,25,26)$. We therefore examined sera from the monoand bicongenic strains for their glomerular-binding potential, or "nephrophilicity." Both male (mean \pm SEM for $\mathrm{OD}=308.3 \pm 48.4$ ) and female (mean \pm SEM for OD $=577.1 \pm 143.8)$ B $6 . \mathrm{NZMc} 1 \mid \mathrm{c} 7$ sera had significantly higher glomerular-binding autoantibodies compared with B6 (mean \pm SEM $=112.8 \pm 18.9 ; P<0.003$ ), B6.NZMc1 (mean \pm SEM $=82.1 \pm 11.5 ; P<0.001)$, and B6.NZMc7 (mean \pm SEM $=162.3 \pm 60.0 ; P<0.04$ ) sera (Figure 6a). Indeed, the B6.NZMc1 $\mid c 7$ and NZM2410 sera exhibited similar levels of glomerular-binding autoantibodies. Interestingly, B6.NZMc1|c7 female sera exhibited stronger glomerular reactivity compared with age-matched males $(P<0.025)$. Together, Figures 5 and 6 demonstrate that the combined action of Sle 1 and Sle3 is required to generate high titers of autoantibodies that have specificity for not only the different chromatin epitopes (including dsDNA) but also the intact glomeruli. A large cohort of B6.NZMc1 |c7 sera (7-12 months old) were next tested in parallel for their reactivity to the different subnucleosomal epitopes as well as for their glomerular-binding potential. Indeed, the nephrophilic potential of these sera correlated best with their reactivities to dsDNA ( $r=0.76$; Figure $6 \mathrm{~b})$ and less so with the H1/DNA $(r=0.64), \mathrm{H} 3 / \mathrm{H} 4 / \mathrm{DNA}(r=0.63)$, and $\mathrm{H} 2 \mathrm{~A} / \mathrm{H} 2 \mathrm{~B} / \mathrm{DNA}(r=0.54)$ subnucleosomal complexes.

The nephrophilic potential of B6.NZMc1|c7 sera was confirmed using a second, independent source of basement membrane antigens. Matrigel is a soluble basement membrane preparation extracted from EngelbrethHolm-Swarm mouse sarcoma, a tumor rich in extracellular matrix proteins (27). Matrigel reactivity has been shown to correlate well with glomerular binding of lupus sera (19). Unlike sera from the B6 and monocongenic strains (data not shown), B6.NZMc1|c7 sera demonstrated high levels of Matrigel-binding serum autoantibodies, with the females having a higher penetrance than males (Figure 6c). In addition, B6.NZMc1 $\mid$ c7 sera reacted strongly with the major constituents of Matrigel, including heparan sulfate, laminin, and collagen IV, with a similar sex difference (Figure 6c).

Given the differences in the serologic profiles in these strains, we next examined if these strains also demon- 
strated parallel differences in end-organ pathology. In contrast to the $\mathrm{B} 6$ and $\mathrm{B} 6 . \mathrm{NZMc} 1$ mice, B6.NZMc7 mice are known to exhibit a low penetrance of severe GN (12). B6.NZMc1 |c7 mice showed significantly higher penetrance of severe GN compared with the monocongenics $\left(P<10^{-5}, \chi^{2}\right.$ test), as demonstrated in Figure $6 \mathrm{~d}$. Although B6.NZMc1|c7 females exhibited higher rates of severe GN relative to B6.NZMc1|c7 males, this difference was not statistically significant. Sixty-two percent of the B6.NZMc1|c7 mice with severe GN exhibited a proliferative pattern of GN, whereas most of the others had a mesangiopathic pattern of disease. Consistent with these histologic differences, the bicongenic mice exhibited significantly higher mortality compared with the monocongenics $\left(P<10^{-6}, \chi^{2}\right.$ test), with females faring worse than males $\left(P<0.02, \chi^{2}\right.$ test). Interestingly, the NZM2410 mice had even higher mortality rates than the bicongenics $\left(P<10^{-6}, \chi^{2}\right.$ test; Figure $\left.6 \mathrm{~d}\right)$.

\section{Discussion}

Lupus is a polygenic disease, and more than a dozen loci have been implicated in murine lupus (reviewed in refs.
4-6). However, this study shows that on a normal B6 background, the combined impact of just 2 loci, Sle1 on chromosome 1 and Sle 3 on chromosome 7, may be sufficient to recreate most of the immunophenotypes seen in the NZM2410 strain. Sle 1 by itself leads to hypergammaglobulinemia, a break in tolerance to chromatin, and a modest expansion of activated lymphocytes. Serum autoantibodies elicited by Sle1 preferentially target the most exposed determinants on native chromatin, but not dsDNA or basement membrane antigens. Consequently, perhaps, this strain is free of severe GN $(12,14)$. In contrast, Sle 3 leads to impaired activation-induced cell death of T cells, elevated CD4/CD8 ratios, a moderate expansion of activated lymphocytes, hypergammaglobulinemia, and low-grade seroreactivity to all chromatin components (12). When these 2 susceptibility alleles are combined, they mediate the development of fatal lupus nephritis, a result indicating that their phenotypes are interactive, or epistatic. These results, together with the lower penetrance of fatal disease in B6.NZMc1 $\mid$ c7 mice (which have only 2 susceptibility alleles) compared with NZM2410 mice (which have at least 4 susceptibility alleles), are consistent

c

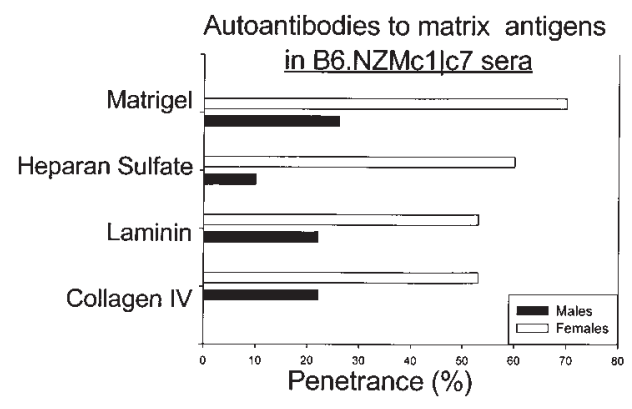

d

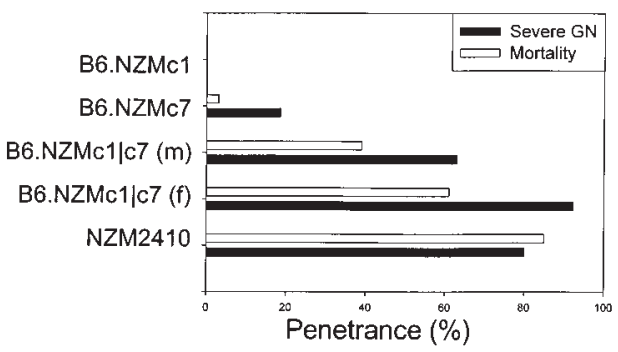

\section{Figure 6}

Nephrophilic autoantibodies and severe GN in B6.NZMc1|c7 mice. (a) The presence of glomerular-binding autoantibodies was assayed by ELISA, using sera from 9- to 12-month-old B6 $(n=10)$, B6.NZMc1 $(n=11)$, B6.NZMc7 $(n=20)$, B6.NZMc1|c7 $(n=16$ females, 10 males), and NZM2410 $(n=10)$ mice. Both male and female B6.NZMc1 $\mid c 7$ mice had significantly higher glomerular-binding autoantibodies compared with B6 ( $P<0.003)$, B6.NZMc1 $(P<0.001)$, and B6.NZMc7 $(P<0.04)$ mice. Indeed, the B6.NZMc1|c7 and NZM2410 mice had similar levels of glomerular-binding autoantibodies. Finally, B6.NZMc1 $\mid$ c7 females had significantly higher levels of these antibodies compared with males $(P<0.025)$. (b) Serum samples from 7- to 12-month-old B6.NZMc1|c7 mice $(n=46)$ were assayed in parallel for a variety of autoantibodies. Shown on the scatter plot are the reactivities of these individual sera with glomeruli, as compared with their reactivities to dsDNA, displayed as raw ODs. The correlation coefficient ( $r$ ) between these 2 specificities was 0.76 . (c) B6.NZMc1|c7 sera show strong reactivity to a variety of basement membrane matrix antigens. Each bar represents the percentage of 9- to 12-month-old B6.NZMc1|c7 males $(n=23)$ or females $(n=17)$ that are seropositive for antibodies specific for Matrigel, heparan sulfate, laminin, or collagen IV. The cutoff for defining seropositivity was set at 2 SD above the mean levels seen in a panel of 12 B6 mice, aged 9 months. (d) The penetrance of severe GN (open bars) and mortality (filled bars) by 12 months of age in B6 ( $n=20$ ), B6.NZMc1 $(n=30)$, B6.NZMc7 $(n=22)$, B6.NZMc1 $\mid c 7$ (19 males, 15 females), and NZM2410 mice $(n=39-55)$. As discussed in the text, the B6.NZMc1 |c7 mice showed significantly higher penetrance of GN compared with the monocongenic $\left(P<10^{-5}, \chi^{2}\right.$ test $)$. Likewise, the bicongenic mice exhibited significantly higher mortality compared with the monocongenics $\left(P<10^{-6}, \chi^{2}\right.$ test) strains, with females faring worse that the males $\left(P<0.02, \chi^{2}\right.$ test $)$. The NZM2410 mice had even higher mortality rates than the bicongenic mice $\left(P<10^{-6}, \chi^{2}\right.$ test $)$. 


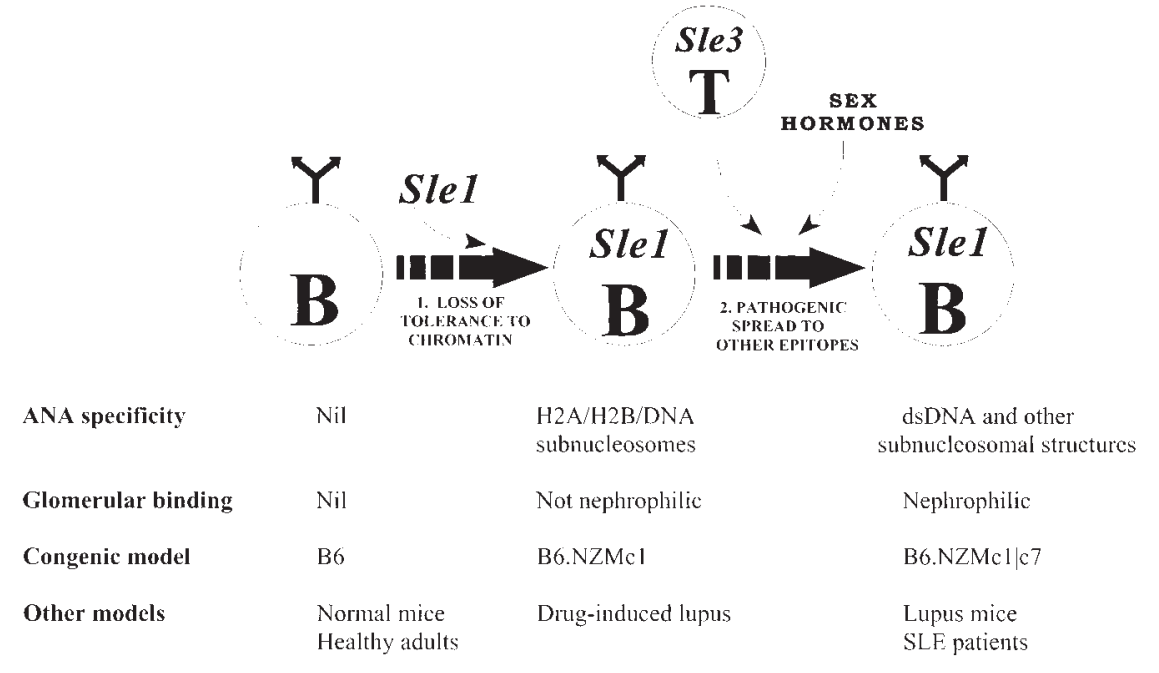

Figure 7

Recipe for nephrophilic autoantibodies in lupus. The data presented in this communication lends support to a two-step recipe for generating nephrophilic autoantibodies and a multi-step model of lupus pathogenesis, as detailed in Discussion. The first step, in effect, breaches tolerance to chromatin. Sle1 is a prototype gene that has the potential to effect this. Importantly, Sle1 triggers the formation of non-nephrophilic anti$\mathrm{H} 2 \mathrm{~A} / \mathrm{H} 2 \mathrm{~B} / \mathrm{DNA}$ ANAs in a B cell-intrinsic fashion (53). Although the phenotype in the B6.NZMc1 mice closely resembles the clinical phenotype observed in drug-induced lupus, it is by no means clear if they share underlying pathogenic mechanisms (54, 55). A second set of genes (as exemplified by Sle3, possibly expressed by T cells) and female sex hormones might then act to facilitate the pathogenic maturation of the initial ANA response, leading to nephrophilicity. It is tempting to speculate that the aberrant B cells and T cells triggered by these genetically distinct pathways might be engaged in enhanced bidirectional T-B collaboration, leading to the exaggerated lymphocyte hyperactivity observed in this strain (Figures 2-4 and Table 2). Although the variegated, nephrophilic autoantibody response generated by the combined impact of these 2 sets of genes may be sufficient to inflict progressive renal disease, susceptibility to end-organ damage may be under the control of additional genetic events.

with a threshold liability model of disease susceptibility in the pathogenesis of lupus, as proposed earlier (9).

The coexpression of Sle1 and Sle 3 triggers significant splenomegaly, with early expansion of activated B cells and $\mathrm{CD}^{+} \mathrm{T}$ cells, and significant hypergammaglobulinemia - not unlike the phenotypes seen in the NZM2410 lupus strain (Tables 1 and 2; Figures 2 and 4). Splenomegaly is a prominent phenotype in all murine models of lupus (22). In the NZB-based models (including the NZM2410 strain), a variety of factors have been suspected of being responsible for splenomegaly $(22,28)$. These include robust lymphocytic, plasma cell, or reticulum cell hyperplasia, changes secondary to hemolytic anemia, and B1 cell expansions and lymphomas. The present study model appears to have dissected out 1 of these triggers of splenomegaly: robust and chronic lymphocytic activation, triggered by the epistatic interaction of 2 distinct lupus susceptibility genes. It is relevant to note that the B6.NZMc1 $\mid \mathrm{c} 7$ bicongenic mice do not have B1 cell expansions (Table 2) or evidence of hemolytic anemia (data not shown). It is evident that the increases in absolute cell numbers and cell size (i.e., the increased numbers of blasts, as shown in Table 2) are major contributors to the observed splenomegaly. In addition, histologic examination of these spleens revealed generalized hyperplasia with prominent germinal centers (data not shown). Finally, these findings also imply that an expansion of B1 cells is not necessary for the generation of nephrophilic autoantibodies in this model.

The epistatic interaction of Sle 1 with Sle3 also appears to be responsible for an intriguing spectrum of poten- tially pathogenic serum autoantibodies, which are also present in NZM2410 lupus mice. Agewise analysis of B6.NZMc1 $\mid$ c7 sera reveals a gradual maturation of the ANA profiles, initially targeting the $\mathrm{H} 2 \mathrm{~A} / \mathrm{H} 2 \mathrm{~B} / \mathrm{DNA}$ subnucleosomes and then progressively involving all other chromatin epitopes (Figure 5, b and c), as has been reported to occur in murine and human lupus (29-31). It is important to note that the maturation of the ANA response does not occur in the monocongenic strains. Thus, although the bicongenic strain exhibits anti$\mathrm{H} 2 \mathrm{~A} / \mathrm{H} 2 \mathrm{~B} / \mathrm{DNA}$ ANA levels as high as those found in B6.NZMc1 monocongenic mice, B-cell supernatant and sera from the bicongenic mice also exhibit significantly more anti-dsDNA ANAs (Figures 3 and 5). This maturation of the ANA response, triggered by the epistatic interaction of Sle 3 with Sle1, is clearly accentuated in females (Figure 5, b and c).

Although such a maturation of the ANA response profile has been well documented in murine and human lupus, the pathogenic relevance of these different specificities of ANAs in disease is less obvious. In particular, the relative importance of anti-H2A/H2B/DNA versus antidsDNA ANAs in disease pathogenesis is still open to investigation. The findings in our congenic mice are consistent with the observations in other lupus-prone mice $(32,33)$, in that mice that only have anti-H2A/H2B/DNA ANAs (without the simultaneous presence of anti-dsDNA antibodies) are free of GN, whereas mice with anti-dsDNA antibodies (accompanied by the other subnucleosomal specificities) begin to demonstrate GN with a high penetrance. Based on these studies, it is reasonable to assign a 
more direct pathogenic role for anti-dsDNA antibodies in disease. Indeed, direct antibody transfer studies have clearly demonstrated that anti-dsDNA antibodies can inflict renal pathology (34). Also consistent with this view is the observation that patients with drug-induced lupus who exhibit serum anti-H2A/H2B/DNA antibodies (in the absence of anti-dsDNA antibodies) do not go on to develop GN $(35,36)$. However, it is intriguing to note that among the lupus patients seroprofiled by Burlingame et al. (31), anti-chromatin and anti-H2A/H2B/DNA (rather than anti-dsDNA) ANAs correlated best with proteinuria. Further studies are thus warranted to define the contexts under which the different subnucleosomal specificities might lead to pathology.

An additional parameter with which to study and classify autoantibodies in lupus has been furnished by the advent of the glomerular-binding assay. Antibodies identified by this assay as being nephrophilic have been shown to be associated with $\mathrm{GN}(21,26)$. Consistent with these studies, Budhai et al. (27) have also noted that patients with anti-dsDNA ANAs and renal disease had significantly higher levels of nephrophilic autoantibodies compared with patients without renal involvement. This additional feature, nephrophilicity, also distinguishes B6.NZMc1 sera from that of B6.NZMc1|c7 (Figure 6a). Indeed, in B6.NZMc1 $\mid \mathrm{c} 7$ mice, the maturation of the ANA response to acquire dsDNA reactivity correlates well with their nephrophilic potential (Figure 6b) and the incidence of GN (Figure 6d). Cross-absorption studies to determine if the same set of antibodies is responsible for both the dsDNA and the glomerular binding reactivities have been inconclusive (data not shown). It is certainly possible that differing, although overlapping, sets of antibodies are responsible for these 2 specificities. Presently, monoclonal antibodies are being derived from these strains to understand the molecular relationships and pathogenic potential of these diverse specificities.

These findings lend support to a model in which pathogenic autoantibodies in lupus arise through 2 genetically determined steps (Figure 7). Loci such as Sle1 may serve primarily to breach tolerance to chromatin, leading to high titers of ANAs that react predominantly with $\mathrm{H} 2 \mathrm{~A} / \mathrm{H} 2 \mathrm{~B} / \mathrm{DNA}$ subnucleosomes. Although these sera stain Hep-2 nuclei strongly (and this assay is commonly used as a diagnostic test for lupus), they are not nephrophilic, and these mice are not nephritic. The identity of Sle1 and why only chromatin is targeted remain unknown. Although we know of no other genes that selectively break tolerance to chromatin, it appears that loci equivalent in function, and possibly syntenic in position, to murine Sle1 also play a critical role in human $\operatorname{SLE}(37,38)$.

Having breached tolerance to chromatin, the "pathogenic maturation" of the innocuous, primary ANA response requires additional genetic input. Loci such as Sle 3 are likely to facilitate the diversification of the targeted B-cell epitopes, to encompass a wider spectrum of self-antigens. The initially formed anti-H2A/H2B/DNA ANAs may serve as the substrates for this process, but this needs to be demonstrated. We hypothesize that $\mathrm{T}$ cells bearing Sle3 (or other equivalent molecules that impact T-cell activation and/or activation-induced cell death) may be the prime movers in this second phase, which culminates in the generation of autoantibodies targeting all chromatin components (including dsDNA), as well as glomerular basement membrane antigens.

Although the specific genes that mediate these steps may differ, a similar series of events is likely to be operative in other murine models, and perhaps in human lupus as well. Another distinct example of this model could be the MRL/lpr murine lupus strain (39). The lpr allele leads to the formation of pathogenic ANAs and lupus nephritis when crossed onto the MRL background, but not when crossed onto several other strains (40). Importantly, $l p r / l p r$ T cells exhibit phenotypes that overlap with those impacted by Sle 3 (15). Thus, it is reasonable to posit that in the presence of an MRL background gene(s) that breaches tolerance to chromatin (like Sle1 does), the $\mathrm{lpr}$ allele might serve to drive pathogenic autoantibody maturation, leading eventually to disease. Experiments to verify this hypothesis are in progress.

Despite the apparent simplicity of the presented model, the sequence of events leading to GN in human and murine lupus is likely to be more complex. Indeed,

Table 2

Lymphocyte subsets in spleens of 9-to 12-month-old B6 congenics and controls.

\begin{tabular}{|c|c|c|c|c|c|c|c|}
\hline & $\begin{array}{c}\text { B6 } \\
(n=22-30)\end{array}$ & $\begin{array}{l}\text { B6.NZMC1 } \\
\quad(n=13)\end{array}$ & $\begin{array}{l}\text { B6.NZMC7 } \\
(n=14-20)\end{array}$ & $\begin{array}{l}\text { B6. NZMc1 } \mid c 7 \\
(n=12)\end{array}$ & $\mathrm{P}^{\mathrm{c1}}$ & $\mathrm{p}^{\mathrm{c7}}$ & $\begin{array}{l}\text { NZM2410 } \\
(n=12-20)\end{array}$ \\
\hline Total splenocytes $\times 10-6$ & $93 \pm 3.5$ & $124 \pm 19.7$ & $105 \pm 5.9$ & $176 \pm 20.9$ & A & B & $172 \pm 36.6$ \\
\hline$\% \mathrm{~B}_{220^{+}}(\mathrm{B}$ cells $)$ & $51.1 \pm 1.7$ & $54.7 \pm 2.4$ & $46.9 \pm 2.6$ & $50.2 \pm 1.9$ & & & $42.9 \pm 3.2$ \\
\hline$\%$ B cell blasts & $23.7 \pm 1.4$ & $24.7 \pm 0.4$ & $19.1 \pm 2.2$ & $42.3 \pm 3.6$ & C & C & $41.4 \pm 4.7$ \\
\hline \%B220+, CD23lo (B1) & $14.2 \pm 1.7$ & $10.1 \pm 0.8$ & $11.2 \pm 1.0$ & $15.6 \pm 2.8$ & & & $19.3 \pm 2.0$ \\
\hline$\% \mathrm{~B} 220^{+}, \mathrm{CD} 5+(\mathrm{B} 1 \mathrm{a})$ & $5.1 \pm 0.5$ & $4.3 \pm 0.4$ & $4.4 \pm 0.4$ & $4.2 \pm 0.7$ & & & $17.2 \pm 1.5$ \\
\hline$\% \mathrm{CD}^{+} \mathrm{T}$ cells & $18.3 \pm 0.6$ & $17.2 \pm 1.5$ & $21.7 \pm 1.4$ & $27.3 \pm 1.9$ & C & A & $33.6 \pm 2.2$ \\
\hline$\% \mathrm{CD}^{+} \mathrm{T}$ cells & $15.8 \pm 0.8$ & $13.6 \pm 0.9$ & $13.9 \pm 1.2$ & $9.7 \pm 0.8$ & B & B & $4.8 \pm 0.4$ \\
\hline CD4 : CD8 ratio & $1.2 \pm .05$ & $1.3 \pm 0.1$ & $1.7 \pm 0.1$ & $3.1 \pm 0.3$ & C & C & $7.3 \pm 0.6$ \\
\hline$\% C D 25^{+}$CD4 T cells & $17.3 \pm 1.7$ & $22.3 \pm 2.4$ & $23.8 \pm 1.5$ & $21.3 \pm 0.7$ & & & $25.6 \pm 5.4$ \\
\hline$\%$ CD $69{ }^{+}$CD4 T cells & $21.9 \pm 2.1$ & $28.9 \pm 2.7$ & $33.1 \pm 2.1$ & $40.5 \pm 2.2$ & B & A & $39.1 \pm 4.0$ \\
\hline \%CD45RBlow CD4 T cells & $30.9 \pm 5.9$ & $33.8 \pm 8.2$ & $48.9 \pm 10.7$ & $78.4 \pm 2.0$ & B & A & $73.2 \pm 12.6$ \\
\hline
\end{tabular}

Tabulated are the mean ( \pm SEM) values of lymphocyte subsets with different surface phenotypes in the spleens of 9- to 12-month-old mice. In the case of NZM2410, the data were obtained from 5- to 8-month-old (terminal) mice, by which age $>80 \%$ are afflicted with GN. Also shown are the percentages of all $\mathrm{B} 220^{+}$cells that were blasts (as defined by size, as described in Methods) and the percentages of CD4 ${ }^{+} \mathrm{T}$ cells that were positive for CD25 or CD69, or had low levels of CD45RB. $\mathrm{p}^{\mathrm{c} 1}$ Student's $t$-test, comparing B6.NZMc1 mice to B6.NZMc1 micep ${ }^{\mathrm{c}}$ Student's $t$-test, comparing B6.NZMc1|c7 mice to B6.NZMc7 mice ASignificantly different, $P<0.05$; ${ }^{B}$ Significantly different, $P<0.01$; 'CSignificantly different, $P<0.001$. 
the correlation between anti-dsDNA seropositivity, nephrophilicity of the sera, and GN is not perfect. Not all anti-dsDNA ANAs have disease potential, and the molecular footprints of pathogenicity are slowly being uncovered (41-43). Moreover, subsets of lupus patients have been noted to have nephrophilic sera in the absence of anti-dsDNA antibodies (27). Finally, the presence of nephrophilic autoantibodies in some lupus patients may not be sufficient for renal disease (26), suggesting that additional mechanisms (and genes) may be necessary to facilitate end-organ damage. In this context, one cannot exclude the possibility that the Sle loci are contributing to $\mathrm{GN}$ by additional mechanisms, beyond their impact on the nature of the autoantibodies. Of relevance to this is the presence of mild to moderate GN (albeit at a low penetrance) in the B6.NZMc7 monocongenics (12). Ongoing studies are aimed at dissecting out the pathogenic events in the end-organs of these congenic strains.

The mode by which nephrophilic antibodies bind glomeruli still remains uncertain. Some studies lend support for direct antibody cross-reactivity with glomerular basement membrane components, including collagen, laminin, and heparan sulfate, very often with pathogenic consequences $(27,44-49)$. As gauged by ELISA cross-reactivity and molecular sequence comparison, this class of autoantibodies appears to overlap ANAs (36). In other words, the same pathogenic process might be responsible for generating both classes of autoantibodies in lupus, and this could also be true of the specificities depicted in Figure 6c. On the other hand, others have demonstrated how nephrophilic antibodies might use antigenic bridges composed of nucleosomes, histones, and/or collagen to bind glomeruli (19, $26,50)$. In the present study, DNase treatment of either the sera or the glomerular substrates did not significantly affect the level of nephrophilicity of the B6.NZMc1 $\mid \mathrm{c} 7$ sera, and premixing the B6.NZMc1 sera with histone/DNA complexes did not enhance their nephrophilicity (data not shown). These observations suggest that the differences in the nephrophilic potential of these 2 sera are due to intrinsic differences in their constituent antibodies, and are not dependent on the availability of nuclear materials in the respective sera that may otherwise serve as antigenic bridges for glomerular binding.

Sle1 and Sle 3 have been described in this manuscript as if they were single genes. Since the congenic intervals are fairly large, it is certainly possible that 2 or more genes within the study intervals are actually contributing to the observed phenotypes. Ongoing studies with congenics bearing shorter genomic intervals will address this issue. It will also be of interest to see how the other lupus susceptibility loci (on other chromosomes) actually interact with Sle1 and Sle 3 to accentuate disease. In this context, despite the high penetrance of severe GN, B6.NZMc1|c7 mice exhibit significantly lower mortality than do the parental NZM2410 mice (Figure 6d). Ongoing studies reveal that additional genetic input (e.g., from Sle2) might be important to attain higher mortality (manuscript in preparation). At present, it is not clear if these additional factors promote mortality by aggravating end-organ damage secondary to autoanti- body deposition, or by contributing to B-cell tumors that have been well documented in the NZM2410 and other NZB-related strains $(24,30)$.

Finally, aside from the genetic load, environmental and hormonal factors are also likely to modulate both pathogenic steps diagrammed in Figure 7. Almost all observed phenotypes in the bicongenic strain appear to be more pronounced in females. A wide body of literature supports the notion that the gender bias in lupus is attributable to sex hormones (51). Interestingly, the pleiotropic effects of sex hormones on the immune system also include strong impacts on thymocyte development and suppressor T-cell function (52). It is therefore tempting to speculate that although female sex hormones may have a subtle impact on breaching tolerance to chromatin (14), their more pronounced impact appears to target the second step-pathogenic autoantibody maturation, which is presumably a T cell-dependent event. In conclusion, these congenic strains reveal a minimal recipe for the genesis of nephrophilic autoantibodies in lupus, with contributions from genes that breach tolerance to chromatin, genes that appear to drive pathogenic autoantibody maturation, and hormonal influences.

\section{Acknowledgments}

We thank Syamal Datta and Eric Sobel for critical reading of the manuscript, and FeiYan Liu, Kim Blenman, Jocelyn Tulsian, and Maria Kontaridis for their technical contributions during various phases of this work. This work was supported by grants from the National Institutes of Health (PO1 AI39824 and R29 AR-44894) and the National Arthritis Foundation. C. Mohan is the recipient of the Robert Wood Johnson Jr. Arthritis Investigator Award.

1. Mohan, C., and Datta, S.K. 1995. Lupus: key pathogenic mechanisms and contributing factors. Clin. Immunol. Immunopathol. 77:209-220.

2. Theofilopoulos, A.N. 1995. The basis of autoimmunity. I. Mechanisms of aberrant self-recognition. Immunol. Today. 16:90-98.

3. Kotzin, B.L. 1996. Systemic lupus erythematosus. Cell. 85:303-306.

4. Wakeland, E.K., Morel, L., Mohan, C., and Yui, M. 1997. Genetic dissection of lupus nephritis in murine models of SLE [review]. J. Clin. Immunol. 17:272-281.

5. Vyse, T.J., and Todd, J.A. 1996. Genetic analysis of autoimmune disease [review]. Cell. 85:311-318.

6. Kono, D.H., and Theofilopoulos, A.N. 1996. Genetic contributions to SLE [review]. J. Autoimmun. 9:437-452.

7. Rudofsky, U.H., Evans, B.D., Balaban, S.L., Mottironi, V.D., and Gabrielsen, A.E. 1993. Differences in expression of lupus nephritis in New Zealand mixed H-2z homozygous inbred strains of mice derived from New Zealand black and New Zealand white mice. Origins and initial characterization. Lab. Invest. 68:419-426.

8. Mohan, C., Morel, L., Yang, P., and Wakeland, E.K. 1997. Splenic B1a cell expansion in NZM2410 lupus strain, with strong antigen presenting capability. Arthritis Rheum. 41:1652-1662.

9. Morel, L., Rudofsky, U.H., Longmate, J.A., Schiffenbauer, J., and Wakeland, E.K. 1994. Polygenic control of susceptibility to murine systemic lupus erythematosus. Immunity. 1:219-229.

10. Wakeland, E.K., Morel, L., Achey, K., Yui, M.E., and Longmate, J.A. 1998. Speed congenic: a classic technique moves into the fast lane (relatively speaking). Immunol. Today. 18:473-477.

11. Morel, L., Yu, Y., Blenman, K.R., Caldwell, R.A., and Wakeland, E.K. 1996. Production of congenic mouse strains carrying genomic intervals containing SLE-susceptibility genes derived from the SLE-prone NZM2410 strain. Mamm. Genome. 7:335-339.

12. Morel, L., et al. 1997. Functional dissection of SLE pathogenesis using congenic mouse strains. J. Immunol. 158:6019-6028.

13. Mohan, C., Morel, L., Croker, B., Yang, P., and Wakeland, E.K. 1997. Genetic dissection of SLE pathogenesis: Sle2 on murine chromosome 4 leads to B-cell hyperactivity. J. Immunol. 159:454-465.

14. Mohan, C., Alas, E., Morel, L., Yang, P., and Wakeland, E.K. 1997. Genetic dissection of SLE pathogenesis: Sle1 on murine chromosome 1 leads to loss of tolerance to $\mathrm{H} 2 \mathrm{~A} / \mathrm{H} 2 \mathrm{~B} / \mathrm{DNA}$ subnucleosomes. J. Clin. Invest. 
101:1362-1372

15. Mohan, C., Yu, Y., Morel, L., and Wakeland, E.K. 1999. Genetic dissection of SLE pathogenesis: Sle3 on murine chromosome 7 impacts T cell activation, differentiation and cell death. J. Immunol. In press.

16. Mohan, C., Adams, S., Stanik, V., and Datta, S.K. 1993. Nucleosome: a major immunogen for pathogenic autoantibody-inducing $\mathrm{T}$ cells of lupus. J. Exp. Med. 177:1367-1381.

17. Burlingame, R.W., and Rubin, R.L. 1990. Subnucleosome structures as substrates in enzyme-linked immunosorbent assays. J. Immunol. Methods. 134:187-199.

18. Losman, M.J., Fasy, T.M., Novick, K.E., and Monestier, M. 1992. Monoclonal autoantibodies to subnucleosomes from a MRL/Mp(-)+/+ mouse. Oligoclonality of the antibody response and recognition of a determinant composed of histones H2A, H2B, and DNA. J. Immunol. 148:1561-1569.

19. Van-Bruggen, M.C., et al. 1997. Antigen specificity of anti-nuclear antibodies complexed to nucleosomes determines glomerular basement membrane binding in vivo. Eur. J. Immunol. 27:1564-1569.

20. Bernstein, K.A., Valerio, R.D., and Lefkowith, J.B. 1995. Glomerular binding activity in MRL lpr serum consists of antibodies that bind to a DNA/histone/type IV collagen complex. J. Immunol. 154:2424-2433.

21. Bernstein, K., Bolshoun, D., Gilkeson, G., Munns, T., and Lefkowith, J.B. 1993. Detection of glomerular binding immune elements in murine lupus using a tissue-based ELISA. Clin. Exp. Immunol. 91:449-455.

22. Pirani, C.L., and Croker, B. 1994. Handling and processing of renal biopsy and nephrectomy specimens. In Renal pathology: with clinical and functional correlations. C.C. Tisher and B.M. Brenner, editors. J.B. Lippincott. Philadelphia, PA. 1683-1694.

23. Pirani, C.L., Pollack, V.E., and Schwartz, R.S. 1964. The reproducibility of semiquantitative analyses of renal histology. Nephron. 1:230-237.

24. Theofilopoulos, A.N., and Dixon, F.J. 1985. Murine models of systemic lupus erythematosus. Adv. Immunol. 37:269-390.

25. Izui, S., Berney, T., Shibata, T., and Fulpius, T. 1993. IgG3 cryoglobulins in autoimmune MRL-lpr/lpr mice: immunopathogenesis, therapeutic approaches and relevance to similar human diseases. Ann. Rheum. Dis. 52:48S-54S.

26. Lefkowith, J.B., et al. 1996. Heterogeneity and clinical significance of glomerular-binding antibodies in systemic lupus erythematosus. J. Clin. Invest. 98:1373-1380.

27. Budhai, L., Oh, K., and Davidson, A. 1996. An in vitro assay for detection of glomerular binding IgG autoantibodies in patients with systemic lupus erythematosus. J. Clin. Invest. 98:1585-1593.

28. Lefkowith, J.B., and Gilkeson, G.S. 1996. Nephritogenic autoantibodies in lupus. Current concepts and continuing controversies. Arthritis Rheum. 39:894-903.

29. Kleinman, H.K., et al. 1982. Isolation and characterization of type IV procollagen, laminin, and heparan sulfate proteoglycan from the EHS sarcoma. Biochemistry. 21:6188-6193.

30. East, J. 1970. Immunopathology and neoplasms in New Zealand black (NZB) and SJL/J mice. Progr. Exp. Tumor Res. 13:84-134.

31. Burlingame, R.W., Boey, M.L., Starkebaum, G., and Rubin, R.L. 1994. The central role of chromatin in autoimmune responses to histones and DNA in systemic lupus erythematosus. J. Clin. Invest. 94:184-192.

32. Burlingame, R.W., Rubin, R.L., Balderas, R.S., and Theofilopoulos, A.N. 1993. Genesis and evolution of antichromatin autoantibodies in murine lupus implicates T-dependent immunization with self antigen. J. Clin. Invest. 91:1687-1696.

33. Amoura, Z., et al. 1994. Nucleosome-restricted antibodies are detected before anti-dsDNA and/or antihistone antibodies in serum of MRL-Mp lpr/lpr and +/+ mice, and are present in kidney eluates of lupus mice with proteinuria. Arthritis Rheum. 37:1684-1688.

34. Vlahakos, D.V., et al. 1992. Anti-DNA antibodies form immune deposits at distinct glomerular and vascular sites. Kidney Int. 41:1690-1700.
35. Rubin, R.L., Bell, S.A., and Burlingame, R.W. 1992. Autoantibodies associated with lupus induced by diverse drugs target a similar epitope in the (H2A-H2B)-DNA complex. J. Clin. Invest. 90:165-173.

36. Totoritis, M.C., Tan, E.M., McNally, E.M., and Rubin, R.L. 1988. Association of antibody to histone complex H2A-H2B with symptomatic procainamide-induced lupus. N. Engl. J. Med. 318:1431-1436.

37. Tsao, B.P., et al. 1997. Evidence for linkage of a candidate chromosome 1 region to systemic lupus erythematosus (SLE). J. Clin. Invest. 99:725-731.

38. Moser, K.L., et al. 1998. Genome scan of human systemic lupus erythematosus: evidence for linkage on chromosome 1q in African-American pedigrees. Proc. Natl. Acad. Sci. USA. 95:14869-14874.

39. Cohen, P.L., and Eisenberg, R.A. 1991. Lpr and gld: single gene models of systemic autoimmunity and lymphoproliferative disease. Annu. Rev. Immunol. 9:243-269.

40. Izui, S., et al. 1984. Induction of various autoantibodies by mutant gene lpr in several strains of mice. J. Immunol. 133:227-233.

41. Gilkeson, G.S., et al. 1995. The influence of variable-region somatic mutations on the specificity and pathogenicity of murine monoclonal anti-DNA antibodies. Clin. Immunol. Immunopathol. 76:59-67.

42. Wloch, M.K., Alexander, A.L., Pippen, A.M., Pisetsky, D.S., and Gilkeson, G.S. 1996. Differences in V kappa gene utilization and VH CDR3 sequence among anti-DNA from C3H-lpr mice and lupus mice with nephritis. Eur. J. Immunol. 26:2225-2233.

43. Lefkowith, J.B., et al. 1996. Murine glomerulotrophic monoclonal antibodies are highly oligoclonal and exhibit distinctive molecular features. J. Immunol. 157:1297-1305.

44. Foster, M.H., et al. 1993. Molecular analysis of spontaneous nephrotropic anti-laminin antibodies in an autoimmune MRL-lpr/lpr mouse. $J$. Immunol. 151:814-824.

45. Ben, Y.A., et al. 1995. The urine of SLE patients contains antibodies that bind to the laminin component of the extracellular matrix. J. Autoimmun. 8:279-291.

46. Termaat, R.M., et al. 1993. Antigen-specificity of antibodies bound to glomeruli of mice with systemic lupus erythematosus syndromes. $L a b$. Invest. 68:164-173.

47. Fillit, H., and Lahita, R. 1991. Antibodies to vascular heparan sulfate proteoglycan in patients with systemic lupus erythematosus. Autoimmunity. 9:159-164.

48. Moreland, L.W., Gay, R.E., and Gay, S. 1991. Collagen autoantibodies in patients with vasculitis and systemic lupus erythematosus. Clin. Immunol. Immunopathol. 60:412-418.

49. Ratkay, L.G., Tonzetich, J., and Waterfield, J.D. 1991. Antibodies to extracellular matrix proteins in the sera of MRL-lpr mice. Clin. Immunol. Immunopathol. 59:236-245.

50. Termaat, R.M., et al. 1992. Anti-DNA antibodies can bind to the glomerulus via two distinct mechanisms. Kidney Int. 42:1363-1371.

51. Steinberg, A.D., et al. 1979. Approach to the study of the role of sex hormones in autoimmunity. Arthritis Rheum. 22:1170-1189.

52. Ansar, A.S., Penhale, W.J., and Talal, N. 1985. Sex hormones, immune responses, and autoimmune diseases. Mechanisms of sex hormone action. Am. J. Pathol. 121:531-551.

53. Sobel, E.S., Mohan, C., Morel, L., Schiffenbauer, J., and Wakeland, E.K. 1999. Genetic dissection of SLE pathogenesis: adoptive transfer of Sle1 mediates the loss of tolerance by bone marrow derived B cells. J. Immunol. 162:2415-2421.

54. Kretz-Rommel, A., Duncan, S.R., and Rubin, R.L. 1997. Autoimmunity caused by disruption of central T cell tolerance. A murine model of druginduced lupus. J. Clin. Invest. 99:1888-1896.

55. Yung, R., et al. 1996. Mechanisms of drug-induced lupus. II. T cells overexpressing lymphocyte function associated antigen 1 become autoreactive and causes a lupus-like disease in syngeneic mice. J. Clin. Invest. 97:2866-2871. 